\title{
Engineering practice in Nigerian university-a microcosm of engineering development and practice in developing countries
}

\begin{abstract}
There is a strong link between engineering and development. Engineering as a profession is a call to service by the society. Perhaps next to soldiers, engineers are the most patriotic professionals. However, unlike soldiers they remain servants of society at all times and in all circumstances. Despite her role to the society, engineering profession seems not to be enjoying the respect due to it probably because of failures associated with some engineering projects. This paper focuses on the need to improve on engineering practices for developments in developing countries using Engineering practice in Nigerian Universities as a tool for argument. Purposeful Survey, interview and focus group discussion were carried out among one hundred and twenty (120) reputable firms in Nigeria. The topic was approached through a few projects that the firms have been involved in from the planning stage, some to completion and beyond into the stage of maintenance and monitoring. It is revealed that some factors which are not determined by the engineers themselves impeded progress and full success of engineering practice in developing countries. The key culprit is corruption whose eradication will put the nation on the solid path of effective engineering development and poverty alleviation.
\end{abstract}

Volume 3 Issue 6 - 2017

\author{
Sunday Olufemi Adesogan \\ Civil Engineering Department, University of Ibadan, Nigeria
}

Correspondence: Sunday Olufemi Adesogan, Civil Engineering Department, University of Ibadan, Nigeria, Tel 234-803-326-97I3, Email Sunday.adesogan@fuoye.edu.ng

Received: October 22, 2017 | Published: December 20, 2017

Keywords: engineering, future, development, practices, sustainable

\section{Introduction}

It is a general opinion that the establishment of a department of engineering services in the University system in a developed country will not have the same importance that it would have in a developing country because there are more than enough contracting establishments that could be depended upon to tackle most of the works aspects of the services, so that the engineering services will be mainly concerned with maintenance and repairs of the utility services of the University. In developing countries, however, the engineering services department has to tackle a lot more than is expected of its counterpart in developed countries. You will therefore forgive me if I treat the subject as if it reads "The future of engineering services in the University system in Nigeria - even though I am aware that the condition or situation that obtains in Nigeria is equally applicable to Universities in other developing countries. The Physical plant of a University in developed countries has been described as consisting of Administration buildings, Libraries, Laboratories, Lecture Halls, some residential and re creative facilities, an auditorium, a gymnasium, a hospital and an institute for advanced study and research. This description also fits universities in developing countries; but to this must be added, the provision of living accommodation for all academic staff and for all or most of the students, and a good number of senior and junior Administrative staff, the construction and maintenance of roads, the provision of water, electricity, refuse collection and disposal, sewage system, telephone and transport. In fact the University campus in a developing country is a small town of anything up to some 50,000 people. In University of Ibadan with a student population of about 30,000 , the campus population is between 45,000 and 50,000. Consequently, the engineering services to be provided are like that for a small township with that size of population and in order that these services may be adequately and satisfactorily provided a works, maintenance and transport Department must be established.

The head of such a department, a properly qualified professional engineer is required as he will not only see to the efficient running of the department, he will also have to deal with other engineering consultants when capital works are concerned. A copious example is, when I was appointed to the post of Assistant Director of works in Bowen University, Iwo Osun State of Nigeria, one of the first jobs I tackle was the tarring of the main road that lead to the University. On my arrival, the work had been done by a contractor but no sooner was the job complete than the tarred surface started to disintegrate. I could see immediately that the road was badly constructed as no specification was given to the contractor who was essentially a building contractor. I had to get the contractor to strip the road surface and rebuild it to a specification which I gave him. Luckily, the contractor was anxious to retain the goodwill of the University; he therefore accepted my decision without any argument even though the work had been accepted as completed by the technicians who were in charge before my appointment. Corruption in the construction of public infrastructure has particularly serious implications for developing countries. " "More than any other department in the university, with the possible exception of the registrar's department, the maintenance Department is in constant touch with the lives of staff and students alike. Every new member of staff from the time he sets foot on the campus feels the need to approach the Maintenance Department for his requirements which can be anything from a nail or a screw to a car". There is no end to what you are required to do. You are even called upon to replace blown electric fuses in power plugs. I used to say that members of staff come to the department to ask that their request be carried out yesterday - such used to be their insistence 
on immediate attention at the time. If you do not leave everything you are doing and attend to the request of some members of staff you became a persona non grata and they hit back at you by saying uncomplimentary things about your department.

The future of engineering services in the University Systems in this country will depend on the importance that the country placed on its engineers. Time and again it would appear as if Nigeria believes that it could do without the engineers. Therefore the future of engineering services in the University system will naturally depend on the future of engineering services in the country and incidentally the future of the engineering profession. Day after day our Government continues to pay lip service to the recognition of technology as a sine qua non to our development. New Institutes of Technology are springing up all over the place more as a political expediency than as a real desire to provide technological knowledge to the youths of this country. Like every other aspect of our Higher learning we establish these institutions and failed to either staff them adequately both with regard to number and quantity of neither staff, nor are they properly equipped for the discipline they are establish to impart. The available funds is spread thinly over a proliferation of institutes of higher learning, rather than consolidate well established ones which naturally require more funds for their existence in the present circumstances of economic depression in the country. The result is that the products have not the real foundation on which to build experience. The hysterical cry of our legislators and the information media that our Universities should undertake revenue generating projects is a futile effort to place the blame for shortage of funds on the Universities themselves. No University in this country can undertake revenue that will produce the kind revenue that will make for any appreciable reduction in the subvention which the Government must make for the successful existence of these institutions of higher learning. Universities and Polytechnic have become status symbols for our states in this country and therefore their establishments are highly politicized, and the students are the pawns on the chessboard of politicized education. I hope we will not get to the stage where Government will only recognize the degrees obtained in their own university in preference to all others or that degrees will be awarded by the quota system in our universities. Engineering practices outside the University, receives no less disrespect than their colleagues in practice outside. A focus group discussion and interview with contractors and consultants reveals that engineering practice and development in developing countries are still crude. Let us take a cursory look of engineering practices in Nigeria for the past thirty years.

\section{Engineering and development}

There has been a strong link between engineering and development, whenever any nation or world leader brags about his achievement; it is usually within the context of one engineering feat or the other. In modern days, the United Nations has established some indices of development that has been linked to engineering (Table 1). ${ }^{2}$

Table I United Nations world development indicators

\begin{tabular}{|c|c|c|c|c|}
\hline \multirow{2}{*}{ S. No } & \multirow{2}{*}{ Indicator } & \multicolumn{3}{|c|}{ Link with engineering } \\
\hline & & Direct & Indirect & Strong \\
\hline 1 & Size of Economy & - & - & $\checkmark$ \\
\hline 2 & Quality of Life & $\checkmark$ & - & - \\
\hline 3 & Population and Labour Force & - & $\checkmark$ & - \\
\hline 4 & Poverty & - & $\checkmark$ & - \\
\hline 5 & Distribution of Income or Consumption & $\checkmark$ & - & - \\
\hline 6 & Education & - & - & - \\
\hline 7 & Health & - & - & $\boldsymbol{v}$ \\
\hline 8 & Land Use and Agricultural Productivity & $\checkmark$ & - & - \\
\hline 9 & Water Use, deforestation and Protected Areas & $\checkmark$ & - & - \\
\hline 10 & Energy Use and Emissions & $\checkmark$ & - & - \\
\hline 11 & Growth of the Economy & - & - & $\checkmark$ \\
\hline 12 & Structure of Output & - & - & $\boldsymbol{v}$ \\
\hline 13 & Structure of Demand & - & $\checkmark$ & - \\
\hline 14 & Central Government Finances & - & - & $\checkmark$ \\
\hline 15 & Balance of Payment and International Reserves & - & - & $\checkmark$ \\
\hline 16 & Private Sector Finance & - & - & $\boldsymbol{v}$ \\
\hline 17 & Role of Government in the Economy & & $\checkmark$ & - \\
\hline 18 & Power and Transportation & $\checkmark$ & - & - \\
\hline 19 & Communication, Science and Information Technology & $\checkmark$ & - & - \\
\hline 20 & Global Trade & $\checkmark$ & - & - \\
\hline 21 & Aid and Financial Flow & - & - & $\checkmark$ \\
\hline
\end{tabular}




\section{Methodology}

In carrying out this work, focus group discussions, interviews were held with various engineering firms with a view to stem down the rate of engineering projects' failure. The areas that were looked into include area of practice such as Consultancy (adherence to design standard and specification), construction, monitoring/maintenance, commissioning to project completion, geographical spread of the projects, staffing and intrusions from non-engineering personnel.

\section{Primary areas of practice}

Consultancy within the county has been mainly in 3 primary fields of civil engineering, that is, water resources, highways and transportation as well as structures. Irrigation, drainage and flood control are being handled under water resources while sanitation also forms a significant arm of the firms' operations. Table 2 depicts spread of jobs through the disciplines of the years.

Table 2 Job distribution by discipline and geographical spread over time (source) ${ }^{3}$

\begin{tabular}{|c|c|c|c|c|c|c|c|c|}
\hline Projects & Location & 1987 & 1992 & 1997 & 2002 & 2007 & 2012 & (Presently)2016 \\
\hline \multirow[t]{2}{*}{ Water Resources and related project } & North & 25 & 60 & 50 & 40 & 10 & 10 & Nil \\
\hline & South & 15 & 40 & 50 & 30 & 60 & 40 & 10 \\
\hline \multirow[t]{2}{*}{ Highways \& Transportation } & North & 5 & 15 & 25 & 30 & 25 & 20 & 10 \\
\hline & South & 15 & 60 & 75 & 60 & 50 & 80 & 40 \\
\hline \multirow[t]{2}{*}{ Structures } & North & 20 & 15 & Nil & 45 & 30 & Nil & Nil \\
\hline & South & 30 & 80 & 70 & 120 & 150 & 50 & 50 \\
\hline
\end{tabular}

\section{Geographical spread}

The firms had the whole country as their field of operation considering that consultancy in the past was in limbo. The oil boom was just over and economic recession on, consultants were few, and be it expatriate or indigenous. The few indigenous consultants were concentrated in the south with their scope of practice being mainly structures in buildings. As practices and development of engineering grows in response to the law of demand and supply, the firms had a few projects in the northern and a good load of water scheme (Table 2) refers.

\section{Manpower disposition}

As is to be expected, the firms' professional manpower structures were totally indigenous (Nigeria) within the first few years of operation. Later on some expatriates joined the professional labour force as direct employees of the firms. Prior to this, however, some firms had teamed up with expatriate consulting firms in the execution of some projects especially those with foreign financing. Table 3 shows the professional manpower disposition over the years. It must be ensured that all engineering establishments must have the full compliments consisting of the high level, the middle level and the lower level or junior level to be truly effective. If this normal standard is not achieved, and everyone belongs to the high level manpower, then there will be the need to use high level manpower to do middle level manpower job leading to underutilization of high level manpower, and therefore wastage of manpower., ${ }^{3,4}$ A pointer to engineering development in the country is the underrating of the professionals and proliferation of offices in the country. On the other hand, the act might be a following of the example of some of our Government which have abolished the post of Controller of Works and made the Chief Engineer of each section of the Ministry responsible to whom? Perhaps to an administrative officer who has not the foggiest idea of what the engineers are expected to do. I made that statement because some years ago a high functionary of one of our Government was reported to have said that if he could have his way he would sack all the engineers in the service and give all the jobs to Consultants. But then who are the consultants? Are they not engineers, some of whom have might resigned their appointments form the Service to become consultants? There was also the one time Head of Service of a State who said that after one of his Director Generals had been in the Ministry of Works for three weeks, he was speaking the language of engineers; but I asked him what was the language of engineers, he had no ready answer.

Table 3 Regrouping into public and private sectors looks

\begin{tabular}{lll}
\hline Sectors & Completed & Uncompleted \\
\hline Public & $48 \%$ & $52 \%$ \\
Private & $85 \%$ & $15 \%$
\end{tabular}

\section{Commissioning of design to project completion}

Development of infrastructures has as its ultimate objective the enhancement of the standard of living of the end users, the citizenry. ${ }^{5}$ In effect, a nation that is committed to improvement of advancement must develop and provide basic amenities like potable water, good roads, sanitary environment, good communication network, etc. It is therefore logical and indeed commended that the annual budgets of the Federal and State government have a long list of capital projects that are designed to take care of the most vital areas of developmental needs. Consequently, projects are awarded for study, design, construction, maintenance or combinations of these as the case may be. The pace of development will naturally harmonize with availability of funds.

Going by the firms' experience, a summary of projects status grouped into two (2) broad divisions i.e. completed and uncompleted gives an interesting result thus:

a. Completed $66.5 \%$

b. Uncompleted $33.5 \%$ 
Further analysis by regrouping into public and private sectors looks thus (Table 3).

To arrive at rational or objective basis of comparison minor projects have been excluded from the analysis and other selection parameters take cognizance of project for individuals as opposed to these to serve large communities. An inescapable conclusion from the high proportion of uncompleted projects is that government has shown a low level of communication bordering on insensitivity towards effective planning and execution of projects. Reasons can be adduced to soften the blame like inflation, incompetence of most contractors and so forth. The future efficiency and profitability of any organization is closely linked with the provision of opportunities for an increased involvement of people in their work and with having a realistic interest in this people. ${ }^{6}$ Central to the problems of efficiency and profitability are people and projects, the former requiring participation and the later requiring excellence in design. The natural outcome of allowing and encouraging people to participate in the decisions that closely affect them will be an improvement in quality, output, and acceptance of change, safety and retention of staff. The need and desire for participation throughout industry and in fact society in general is far greater than is generally appreciated. Participation helps to fulfil a human need to be wanted and respected; consequently we can expect a greater escalation of demand for participation.?

\section{Adherence to design standards and specifications}

In the realizations of the several projects that form the basis of development through the provision of the facilities that sustain and improve the quality of human life, engineering designs are carried out and specification are drawn up. These are to ensure quality and durability of end products, functionality and effectiveness, aesthetic, amongst others and sustainable development within the carrying capacity of supporting ecosystems. ${ }^{8}$ All these are the requirements of a good design emanating from a good brief from the Clients. From the survey of engineering development and practices in Nigeria over the past thirty (30) years, a number of factors were found to superimpose themselves on the machinery for effective and sustainable development in the area of design standards and specifications. Some of the most obvious examples of the negative impact of compromise are in road development.

An example is a typical layout of an urban road with:

a. Adequate number of lanes for envisaged traffic.

b. Adequate width for each lane with due consideration for the vehicle classes for or types using the route

c. Provision of parking lanes and lay bys.

d. Provision of pedestrian walkway.

e. Allowance for provision of services, for example, street lighting, water and sewage pipes and telephone cable, some of them through ducts incorporated into the road cross-section.

f. Drainage for the road surface and to intercept runoff from the enveloping environment.

Most of the roads, especially in the urban centers are hardly built to the ideal standard. In a number of projects the clients themselves are responsible for the departure from the idea through the elimination of some of the facilities maybe from cost consideration and funds limitation. Usually, the geometry, pavement structure and drainage provisions are compromised; some or all of these. What then is the result of this trend on the environment? For the example under reference you can expect traffic congestion from reduction of lanes, induced road accidents either from broken down or parked vehicles, crude and un-aesthetic provisions of dangerously exposed wires and cable for electricity and telephone service, road washouts through inadequate drainage provisions and broken road surface as a result of substandard pavement structure not competent to carry the traffic load. The scenario above is common in most urban centres in Nigeria.

\section{Maintenance}

Maintenance is a concept the layman is reasonably familiar with. The topic itself surfaces so often in the form of "maintenance culture" but what is so certain is that most developing nation does not appreciate its importance. Or if she does, her moves in that direction stop at lip service. It must be mentioned in passing that the approach of the individual to maintenance of personal property or equipment is indeed a miniature of the national trend or tendency. ${ }^{9}$ In developed countries due importance is placed on maintenance. National budgets give it due priority. Universities teach it and now tend to approach the subject as a specialized branch of engineering on which you can major. The firms have been involved in projects that evolve eventually as completed new projects - due to the fact that the infrastructures, machinery and equipment within the existing system became nonfunctional prematurely. The cause in most cases was poor (or lack of) maintenance. An important aspect of engineering services in the University is the maintenance of the Physical Plant of the University which I have referred to earlier. Now one of the chief failings of developing countries is their inability to maintain what it has built or constructed. We plunge from one grandiose and expensive scheme to another whilst the previous ones are left to go to rack and ruin due to lack of maintenance, examples abound all over the country. Building fountains, express way, universities etc. none of them has been properly maintained. Mellanby $\mathrm{AO}^{10}$ in his book on the Birth of "University of Ibadan" had something to say about this. He wrote: When large sums have been spent on buildings, sufficient provision for their maintenance has not been made. Over a period of years, under tropical condition where paint and fabric quickly deteriorate, it has been suggested that a sum of as much as 5 per cent of the capital cost of erecting a building Should be made available each year for its maintenance. If we accept this figure then for a building costing N 2,000,000 a sum of N 100,000 will be required each year. Another way of expressing this is to say that for every Naira spent on buildings, and equal sum should be put into an endowment fund to provide an income for their maintenance and upkeep. I think it may be possible to keep the cost of repairs and or redecoration a little below this sum, but allowing for grass cutting, gardens and road repairs, the economy will not be great. The figures quoted by,$^{10}$ that is $5 \%$ of capital cost for maintenance agrees with that used by Ministry of Works and Transport up till 1991 before I left.

\section{Monitoring of performance of completed project}

The monitoring of performance of completed projects should logically be the responsibility of the client/end user. Where maintenance is being carried out in the ideal, some of the functions between the two are overlapping. The data that provide the tool for a decision on maintenance, rehabilitation, upgrading or downright reconstruction for a new system become readily available within ideal maintenance procedures. Also, while it may indeed be obvious that 
the performance is below optimum, the reasons why one would need that the project is studied to map out the most cost effective solution to the problem and the time frame for in application. The case study in this paper is the comprehensive transportation network in Abuja in which a firm was involved at the preliminary design stage. Monitoring became crucial that the Client, Federal Capital Development Authority (FCDA) negotiated to re-engage the firm to assist. The main problem was encroachment on the right-way of the mass transit and highway layout. Engineering recommendations and professional advices are always compromised or neglected. Sometime ago, I got hold of a copy of the University of Ibadan Calendar 1980-82 and looked up the list of Administrative Staff for the Department of Works Maintenance and maintenance only to discover that it was completely omitted. I later discover on enquiry that the omission was corrected by a corrigendum slip. One hopes that the omission was not an indication of the value placed by the University in its Department of Engineering Services. One drawback to the advancement of this country is the continued subjection of the Professionals to the Administrative on the Public Sector particularly in the Government Service. This has been the pattern since our colonial days but it has not changed one bit till now. In fact, the Administrators now regard themselves as professionals. I make bold to say that until the professionals are given their rightful place in the scheme of things in this country, our much desire development will be greatly retarded. This is particularly true which regard to engineering services either in the country as a whole or in our universities.

\section{Phased development programme}

Development projects are usually of the size and nature that have to grow with increasing population. This has to be so since the output of the completed project is designed to "feed" the population. Assuming a population growth rate $2.1 \%$ per annum which is not unusually in Africa, it takes just over 33 years to have twice the initial population to cope with. Also funds are almost invariable a constraint and it becomes expedient to optimize the use of invariably a constraint and becomes expedient to optimize the use of available funds and scale up the capacity of a completed project with time.

For a structural project in buildings, this would mean extension to create additional space; for roads, it could mean additional lanes and/ or upgrading the pavement from laterite to crushed stone base; for water supply it might mean an additional dam on a nearby tributary plus expansion of treatment works and other relevant components.

\section{Case studies ${ }^{\prime \prime}$}

\section{Project one}

\section{Technical information}

a. Commissioned for design in time $\mathrm{t} 1=0$

b. $21.00 \mathrm{~m}$ high dam

c. $46,00 \mathrm{~m} 3 /$ day treatment capacity

d. Ten pumps and $2 \times 1.2 \mathrm{MW}$ diesel generator incorporated

\section{Background and problems}

a. The project to be awarded for construction first in time $t 1=5$ at a cost of $\mathrm{N} 32 \mathrm{~m}$

b. Project was stalled to ban on capital project but resuscitated in time $\mathrm{t} 1=7$ c. The electro-mechanical plant was awarded and equipment supplies to the country in time $\mathrm{t} 1=9$

d. The civil/treatment plant contracts were also awarded for construction in time $\mathrm{t} 1=10$

e. Financing was under a foreign loan

f. The Bank loan was lost in the process of Government's efforts to re-award the project to some other contractors in time $\mathrm{t} 1=11$

g. By time $\mathrm{t} 1=13$, project was being valued at $\mathrm{N} 47 \mathrm{~m}$. plus US $\$ 32 \mathrm{~m}$.

h. Later on, the project passed on to the new state ( after state creation) and federal government guarantee was secured in time $\mathrm{t} 1=20$ for external financing

i. Currently, neither the local nor foreign components of cost have been firmly secured while spiralling inflation would have further escalated project cost.

j. The scheme ran into trouble through delays on the part of government to favour one contractor or the other, loading of contract and constraints on where to source imported component in favour of financier, also at non-competitive rates.

k. What project could survive these take-off problems that have spanned over 20 years? Unfortunately, this is not an unusual pattern in developing Countries like Nigeria.

1. It must be agreed that total unethical and sharp practices mar the development of engineering in developing country making the uninvited guest poverty our permanent neighbour.

\section{Project two}

\section{Technical information}

a. Commissioned in time $\mathrm{t} 1=0$

b. $159 \mathrm{~m}$ span dualize road bridge

c. Design completed in time $\mathrm{t} 1=1$

d. Construction completed in time $\mathrm{t} 1=3$

\section{Problems}

a. No problems for several reasons. The design was promptly carried out on a clean brief. The contract was awarded without delay to an efficient contractor. Consequently, the project was successfully executed.

b. There was no significant deviation from basic design details and specification.

c. This example was brought out to contrast the bleak picture that is more prevalent in contract administration.

d. This example is given to prove that giving all conducive environment, engineers could prove their onions and turn our society to a friendly environment. Adam Mayer [12] said "The respective roles of the "employer", the "engineer", and the "contractor" need to be defined and separated. Current overlapping in the roles of owner, contractor, and engineer in government hampers the development of competitive bidding and effective contract management. The required separation in roles will require extensive training programmes). 


\section{Project three}

\section{Background}

a. Urban Transportation network study and preliminary design completed in June 1981

b. Consortium: Expatriates Consultant

c. Indigenous Consultant

d. A typical cross section allows a totals right-of-way of $73.0 \mathrm{~m}$. This incorporates an $11.0 \mathrm{~m}$ metre reservation within a $29 \mathrm{~m}$ transit way width having bus lanes on either side of the metro reservation.

e. On either side of the transit way reservation are 3-lane express routes plus 2-lane services road.

f. There is allowance for pedestrian traffic and medians for street lighting.

\section{Problems}

a. During development of the project, powerful interest groups or individuals seeking land in premium areas got land allocated to them encroaching on the right-of-way recreated for public transport. And massive encroachment has been reported not only in public transportation reservations but also on green areas and reservations for other development like land fill zones for refuse disposal.

b. Consequently, ideal planning and layouts are compromised. Less than ideal solutions are sought and the end result in most cases is degradation of the environment.

\section{Project four}

\section{Background}

a. The study was commissioned in time $t 1=0$ with a main objective of finding immediate, medium and long term solutions to water supply shortage problem. The ultimate planning horizon was time $\mathrm{t} 1=0$ to time $\mathrm{t} 1=36$.

b. The brief included evolving a tariff structure and an institutional framework for viability and ultimate autonomy.

c. The final report was submitted in time $\mathrm{t} 1=6$ recommending immediate measure with a capacity of 500MLD to be commissioned in the year time $\mathrm{t} 1=11$, the medium term 260MLD to be inputted in time $t 1=19$ and the long term solution, capacity $650 \mathrm{MLD}$ to be commissioned in time $\mathrm{t} 1=27$. This will last Ibadan and environs till time $\mathrm{t} 1=36$. Ibadan will then be supplied a total of $1600 \mathrm{MLD}$ from five (5) waterworks.

d. It was reliably learnt that funds were secured for the finalized of the Master Plan and detailed design of the immediate measure as recommended.

e. Presently (2015) the project is running almost twenty three (23) years behind schedule. It is then considered more appropriate to design the third and last option first. If design is commissioned now the project can be certain of sufficient potable water till year 2021.

f. Revenue returns within 18 months of commissioning (say 2005) is estimated at not less than N1.0 billion with attendant assurance of viability and autonomy.

\section{Problems}

a. Where are we now? The project is yet to be commissioned for design. Funding is no longer available and new avenue for financing the project are still to be found. Spiralling inflation has complicated sourcing of adequate funds. Water borne disease like cholera and typhoid are on the increase. What do we think is happening to the environment?

b. This example is a clear demonstration of what I call government's lip servicing to the welfare of the society and above all corruption in the highest quarter.

\section{Summary and conclusion}

From the general and specific examples given by the experience of notable firms in Nigeria, it has been shown that some factors impeded progress and full success of engineering practice in developing countries. Water supply projects are started and suspended resulting in water shortage and increase in water borne diseases. Sewage pipes are buried and the project abandoned halfway. Roads crack up and the drainage system or lack of it leads to flooding. Traffic congestion is a common feature and refuse disposal is disorganized as no effective handling process has been set up. The result of these lapses is a degraded environment. Major factors responsible for theses lapses have been identified as numerous and deep rooted in our society. The key culprit is corruption whose eradication will put the nation on the solid path of effective engineering development and the enhancement of the environment. It is also concluded that the future of engineering developments in developing worlds at least in Nigeria depends on a number of factors, some of which are not determined by the engineers themselves. However, there is no doubt that the future will be bright or dim depending on whether or not there exists a right relationship between the engineer and the public or the Institutions which he serves. When government funds are no more repeatedly spent on particular projects over and over again, there will be enough resources to meet the need of the society thereby eradicating poverty in the nation.

\section{Acknowledgments}

None.

\section{Conflicts of interest}

The author declares there are no conflicts of interest.

\section{References}

1. Jill Wells. http://www.u4.no/publications/corruption-in-the-constructionof-public-infrastructure-critical-issues-in-project-preparation/

2. Olunlyo VOS. Technology: The Elixir of Development; University of Lagos Press, Nigeria. 2014.

3. JICA survey team. Field survey report on the Landslide Occurrence in Kotmale Lilisland, Sri Lanka. 2015.

4. Olumide AO. Engineering Practice in Nigeria. Journal of Nigerian Society of Engineers. 2012;8(4):12-21.

5. Ologuneru AS. The Role of Engineering as a Tool for National Development. 2015.

6. Carew AL. The Role of the Professional Engineer and Scientist in Sustainable Development. John Wiley \& sons Ltd. 2004.

7. Williams TA. Future of Engineering in Nigeria. Unpublished Lecture at University of Ibadan, Nigeria. 2013. 
8. Ayoade AJ. Housing Today. The Journal of the Association of Housing Corporation of Nigeria. 2014;14(23):38-39.

9. Ajayi DT. An overview of structural service life of building Structure. Longman press Ltd., Ikeja Lagos, Nigeria. 2015.

10. Mellanby AO. The birth of University of Ibadan. Heineman press, Onireke Ibadan, Nigeria. 1950
11. OSOT Associates. A consulting firm at Ibadan, Oyo State Nigeria. 2015.

12. Adam Mayer. On Poor Quality: Corruption and Construction in China. 2016. 